\title{
When is a multidisciplinary approach required in management of intracranial complications of sinonasal inflammatory disorders?
}

\author{
Quando è richiesto un approccio multidisciplinare nella gestione delle complicanze \\ intracraniche delle patologie infiammatorie nasosinusali?
}

\author{
Carla De Vita ${ }^{1}$, Giacomo Sollini' ${ }^{1}$, Matteo Zoli², Diego Mazzatenta², Ernesto Pasquini ${ }^{1}$ \\ ${ }^{1}$ ENT Unit, Surgical Department, AUSL Bologna, Italy; ${ }^{2}$ Center of Pituitary \& Endoscopic Skull Base Surgery IRCCS Neuroscienze di \\ Bologna, Italy
}

\begin{abstract}
SUMMARY
Intracranial complications of sinonasal inflammatory disorders are relatively unusual but can cause significant morbidity and mortality. They often occur in patients with comorbid disorders and immunocompromised but also people without risk factors can be affected. Intracranial complications of acute rhinosinusitis are rare, probably due to oral antibiotics availability, but are less predictable as they often occur in immunocompetent patients without comorbidity. Their management requires a multidisciplinary approach to plan and customize the therapeutic treatment. Intracranial complications of chronic rhinosinusitis are more predictable as they occur often in immunocompromised patient with particularly risk factors. For this reason, a multidisciplinary approach it's important for treatment and mostly for prevention. The aim of this paper is to present an overview of different multidisciplinary management of intracranial complications of sinonasal inflammatory disorders according to their etiology and severity.
\end{abstract}

KEY WORDS: intracranial complications, rhinosinusitis, multidisciplinary management, nasal endoscopy

\section{RIASSUNTO}

Le complicanze intracraniche delle patologie infiammatorie nasosinusali sono relativamente rare, ma presentano un'elevata mortalità e morbidità. Si verificano in soggetti immunodepressi o con diverse comorbidità, ma anche in soggetti immunocompetenti senza particolari fattori di rischio. Le complicanze intracraniche derivanti da rinosinusite acuta sono rare, verosimilmente per la disponibilità di antibiotici per via orale, ma sono le più imprevedibili, poiché spesso si verificano in soggetti immunocompetenti e senza particolari comorbidità. Richiedono una gestione multidisciplinare che coinvolge diversi specialisti per pianificare l'iter terapeutico che deve essere personalizzato in base alla gravità e all'estensione della patologia. Le complicanze intracraniche derivanti da rinosinusiti croniche sono più prevedibili e si verificano in pazienti con particolari fattori di rischio. Per tale motivo è importante per gli altri specialisti riconoscere i primi sintomi per coinvolgere prontamente lo specialista ORL che ha un ruolo importante per la diagnosi e il trattamento chirurgico. Lo scopo di questo lavoro è quello di fornire una panoramica sulla diversa gestione multidisciplinare delle complicanze intracraniche delle patologie flogistiche nasosinusali in base all'eziologia e alla loro gravità.

PAROLE CHIAVE: complicanze intracraniche, rinosinusite, gestione multidisciplinare, endoscopia nasale

\section{Introduction}

Sino-nasal inflammatory disorders can potentially spread to any surrounding structures, including orbital and intracranial cavity ${ }^{1}$. Orbital complications are
Received: November 7, 2020

Accepted: January 31, 2021

Correspondence

Carla De Vita

ENT Unit, Surgical Department, AUSL Bologna, Italy

E-mail: carla.devita@hotmail.it

Funding

None.

Conflict of interest

The Authors declare no conflict of interest.

How to cite this article: De Vita C, Sollini G, Zoli $\mathrm{M}$, et al. When is a multidisciplinary approach required in management of intracranial complications of sinonasal inflammatory disorders? Acta Otorhinolaryngol Ital 2021;41(SUPPL.1):S67-S75. https://doi.org/10.14639/0392-100X-suppl.1-41-2021-07

() Società Italiana di Otorinolaringoiatria e Chirurgia Cervico-Facciale

\section{(c) (1) $(9)$}

This is an open access article distributed in accordance with the CC-BY-NC-ND (Creative Commons Attribution-NonCommercial-NoDerivatives 4.0 International) license. The article can be used by giving appropriate credit and mentioning the license, but only for non-commercial purposes and only in the original version. For further information: https:// creativecommons.org/licenses/by-nc-nd/4.0/deed.en 
more common but intracranial complications of sino-nasal inflammatory disorders (ICSID) are the most serious and life-threatening.

ICSID are relatively unusual due to the wide availability and use nowadays of antibiotics. However these complication may still occur in the clinical practice and represent a severe condition that can cause significant morbidity and mortality if not promptly recognized ${ }^{2-4}$.

ICSID include epidural abscess, subdural abscess, intracerebral abscess, meningitis, and cavernous or superior sagittal sinus thrombosis ${ }^{5}$.

In case of intracranial involvement it is vital to achieve an urgent diagnosis in order to start as soon as possible a proper treatment. The management of these cases requires a multidisciplinary approaches in every single phase ${ }^{6}$. Otolaryngologist, radiologist and neuroradiologist, infectious disease specialist, hematologist, neurologist, neurosurgeon, maxillo-facial surgeon/odontologist: all these figures and others can be involved from the diagnosis to the treatment. Otolaryngologist and neurologist are involved in the clinical diagnosis of ICSID; radiologist and neuroradiologist help to define and locate the primary site of infection and the type of complications; otolaryngologist, neurosurgeon and maxillo-facial surgeon are involved in the surgical management of the patient while infectious disease specialist, neurologist, hematologist and clinicians are involved in the medical management of the infection and patient comorbidities.

There is no universally accepted treatment paradigm for ICSID and that's why the best treatment is probably achieved via an inter-disciplinary perspective ${ }^{1}$. Generally speaking, complications of chronic rhinosinusitis (CRS) are relatively common but ICSID are typically a complication of acute bacterial rhinosinusitis (ABRS) rather than CRS and usually involve indirect spread through hematogenous routes rather than direct spread intracranially through bony defects ${ }^{7}$.

\section{Intracranial complications of ABRS}

Intracranial complications include Pott's puffy tumor, subdural empyema, epidural abscess, brain abscess, cerebritis, meningitis and cavernous venous thrombosis. They are rare, probably because of the worldwide availability of oral antibiotics, and are estimated at 3 cases per million of population ${ }^{8}$. Nevertheless, complications continue to occur, particularly in children or those individuals who are relatively immunocompromised ${ }^{7}$ but can also be seen in adults without comorbidity.

\section{Etiologic mechanisms}

Direct and indirect spread are the two major etiologic mechanism described in literature ${ }^{1,5,9}$. Direct spread is less common, it occurs through either a bony defect or infection of bone lying between the sinuses and the intracranial space. The mechanism of indirect spread is thrombophlebitis of the valveless diploic veins that drain the paranasal sinuses. Infection then can spread intracranially either by propagation of the thrombus or by the release of septic emboli ${ }^{10}$. The indirect spread has been most frequently reported in immunocompetent, young male patients. This predisposition is probably related to their highly vascularized diploic venous system that allows indirect intracranial extension through propagation of septic thrombophlebitis ${ }^{11}$. Complications are most often secondary to frontal sinusitis ${ }^{7}$, but they can also occur in odontogenic sinusitis ${ }^{12}$. Intracranial complications are relatively rare in pediatric populations and mostly affect older children, probably because the frontal sinuses are the last paranasal sinuses to develop. They are generally detectable after five years of age and are poorly developed until the age of $10^{13}$. Usually, polymicrobial infections caused frequently by Streptococcus, Staphylococcus, anaerobic gram-positive cocci, and anaerobic gram-negative bacilli, are responsible for these complications ${ }^{9,14}$.

\section{Complications and symptoms}

Out of the many intracranial complications of ABRS, subdural empyema is the most common one. It occurs as an extension of acute or subacute frontal sinusitis and mostly affects healthy adults. If a rapid progression of this infection occurs, it can lead to increased intracranial pressure and subsequent neurologic deficits or death. Epidural abscess is the most common intracranial complication of sinusitis in children, symptoms are similar to those of subdural empyema but less severe ${ }^{3}$. Epidural and subdural empyema can spread to the brain parenchyma and cause cerebritis and development of brain abscess. Cavernous venous thrombosis is known as the $\mathrm{V}$ stage of Chandler classification as a result of orbital cellulitis, but it can also be a complication of sphenoid, ethmoid, frontal or odontogenic sinusitis as a result of indirect spread mechanism and can lead to the other intracranial complications ${ }^{15}$.

Symptoms frequently observed are fever, headache and mental status changes and are related to increased intracranial pressure, meningeal irritation, and cerebritis ${ }^{15}$. Headache is the most common sign of cerebritis, whereas fever and altered mental status are less common. Further neurologic deficits may be identified in accordance with the affected brain area. Finally, many patients can develop seizure activity as a result of increasing intracranial pressure. 


\section{Multidisciplinary management}

Prompt recognition of intracranial complications of ABRS and multidisciplinary management are extremely important. Imaging is mandatory if central nervous system complications are suspected (CT and contrast enhancement MRI).

Diagnosis and treatment require collaborations between otolaryngologists, infectious disease specialists and neurosurgeons; when there is an odontogenic sinusitis it also include maxillo-facial surgeons/odontologist.

Rapid empiric antibiotic therapy and seizure prophylaxis is indicated:

- penicillins are used to target non-beta lactamase-producing, gram-positive aerobes and anaerobes;

- carbapenems are used for beta-lactamase producing organisms;

- third generation cephalosporins are commonly administered for aerobic gram-negative organisms;

- metronidazole and chloramphenicol, which both penetrate intracranially, provided coverage against anaerobes ${ }^{16}$;

- vancomycin is useful in cases of methicillin-resistant Staphylococcus aureus.

In literature the role of neurosurgical treatment with drainage is clear ${ }^{11,16}$, both in pediatric and adult patients, and is required early to decrease mortality rate and to reduce persistent neurologic deficit especially in larger intracranial abscesses $(>1 \mathrm{~cm})$. Smaller intracranial abscesses $(<1 \mathrm{~cm})$ can be treated with initial medical management with intravenous antibiotics and serial radiologic evaluation to assess for improvement or progression of disease ${ }^{11}$. They can be followed by radiological evaluations after the onset of empiric antibiotic therapy and can be treated with neurosurgical drainage if there is not a clinical and radiological improvement (Clinical case reported in Figure 1: Male 16-year-old, frontal sinusitis treated at home with antibiotic per OS. Two days after, due to persistent symptoms, was required a MRI that showed a huge abscess in the right frontal lobe. A craniotomic drainage of the abscess was carried out via craniotomic route. A long-time antibiotic therapy was performed with complete symptoms resolution and without neurological sequelae. Endoscopic sinus surgery not performed).

If intracranial complications are caused by odontogenic sinusitis the abscessed teeth should be rapidly extracted and the paranasal sinus drained ${ }^{12}$.

The role of Endoscopic sinus surgery (ESS) in intracranial complications of ABRS in controversial. Some authors suggest ESS as an initial management in order to reduce the number of neurosurgical procedures and in some cases to avoid neurosurgical drainage ${ }^{17-19}$. Other studies don't recommend

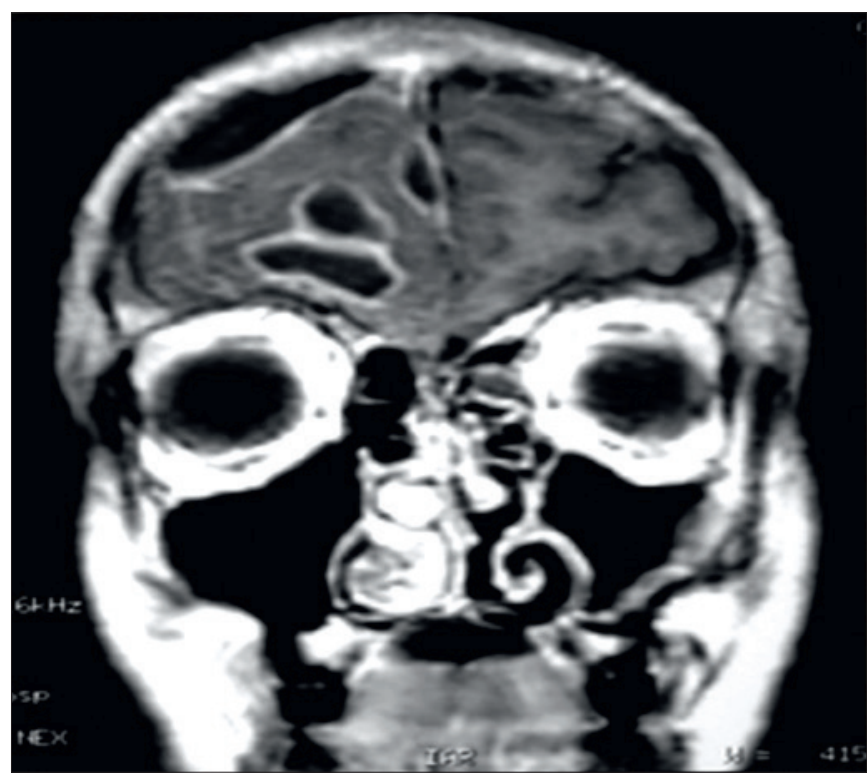

Figure 1. MRI showing a huge abscess in the right frontal lobe.

ESS as the first treatment as it may not prevent neurosurgical drainage and as the most accepted treatment of ABRS is antibiotic therapy with nasal decongestants. Moreover, as most cases of intracranial complications result from indirect spread, can happen that surgical drainage of the sinuses does not seem to have a significant immediate result. On the contrary, ESS is suggested in case of direct spread of the infection from the sinuses to the intracranial space through a bone defect, especially if the defect is near the intracranial abscess ${ }^{11,20}$ (Clinical case reported in Figure 2: Male 3-year-old. Frontal-ethmoidalmaxillary right sinusitis with subdural empyema of right frontal lobe. Treated with antibiotic therapy and combined surgery with craniotomy and ESS; complete clinical and radiological resolution). Finally, ESS can also be postponed if, despite medical therapy, there are still clinical and radiological signs of sinusitis and it is useful to avoid recurrence and mucocele (Clinical case of Figure 3: Male 55-year-old, no comorbidity, hospitalized for fever, headache, rapid deterioration of mental status, coma. At CT acute frontal, ethmoid, maxillary sinus sinusitis and ventricular empyema. MRI found out brain abscess with edema. Treated with ventricular drainage, antibiotic therapy, seizure prophylaxis, followed with several radiological evaluations, ESS performed 25 days after symptoms onset to prevent disease recurrence; Clinical case of Figure 4: Male 17-year-old, Frontal sinusitis with pneumocephalus and meningitis. Disappearance of meningitis after medical treatment, at radiological follow-up persistent frontal dysventilation without cerebrospinal fluid leak and pneumocephalus. In a second time performed right frontal sinusotomy with Draf IIa procedure: resection of the floor of the frontal sinus from 


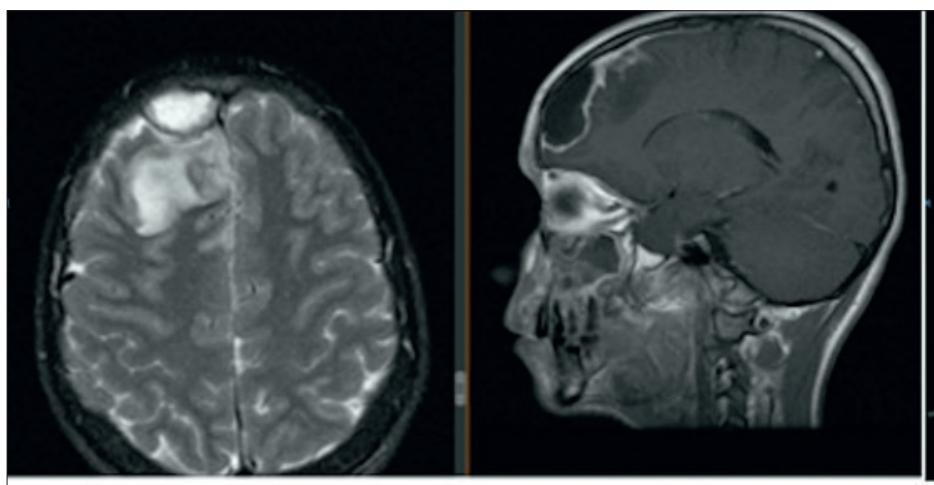

A

B

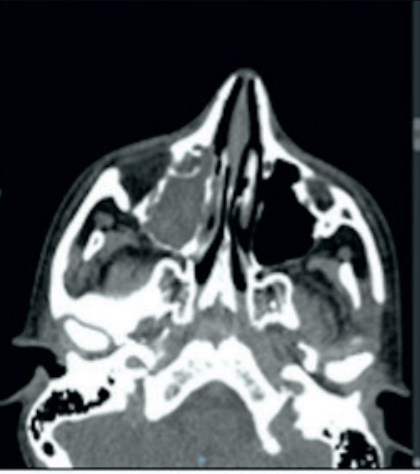

C

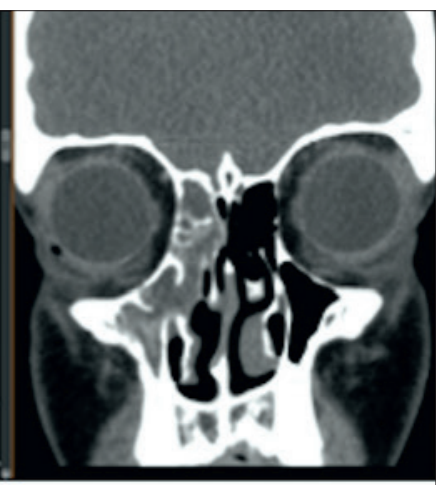

D

Figure 2. (A-B) MRI showing subdural empyema of right frontal lobe; (C-D) CT showing frontal-ethmoidal-maxillary right sinusitis.

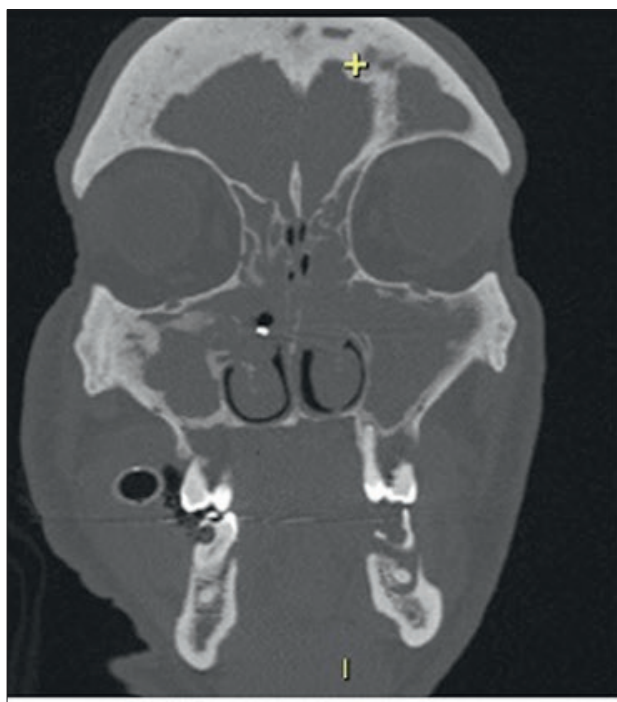

A

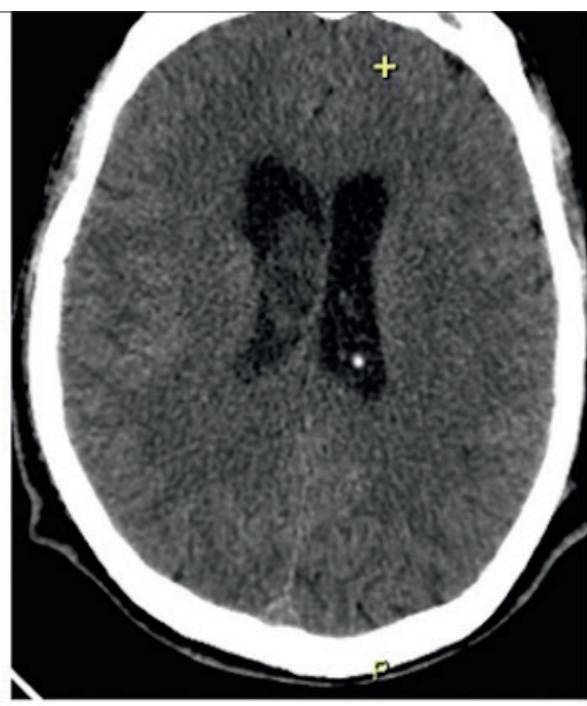

B

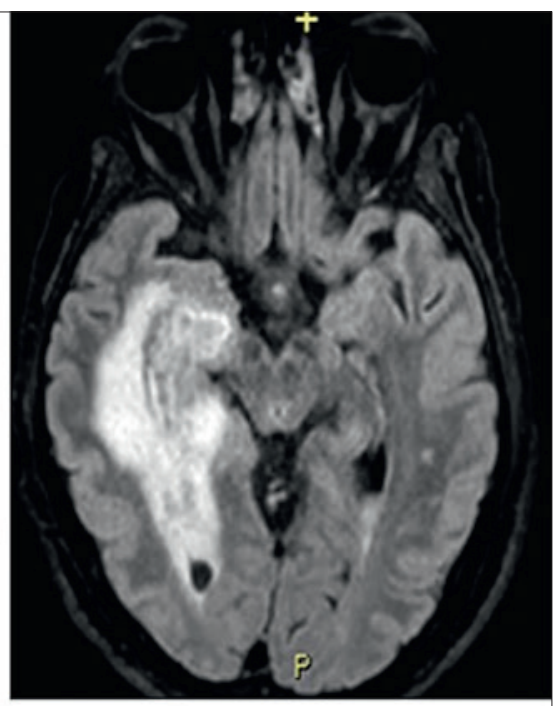

C

Figure 3. (A-B) CT with acute sinusitis (frontal, ethmoid, maxillary sinus; no sphenoid sinus involvement) and ventricular empyema; (C) MRI with brain abscess and edema.

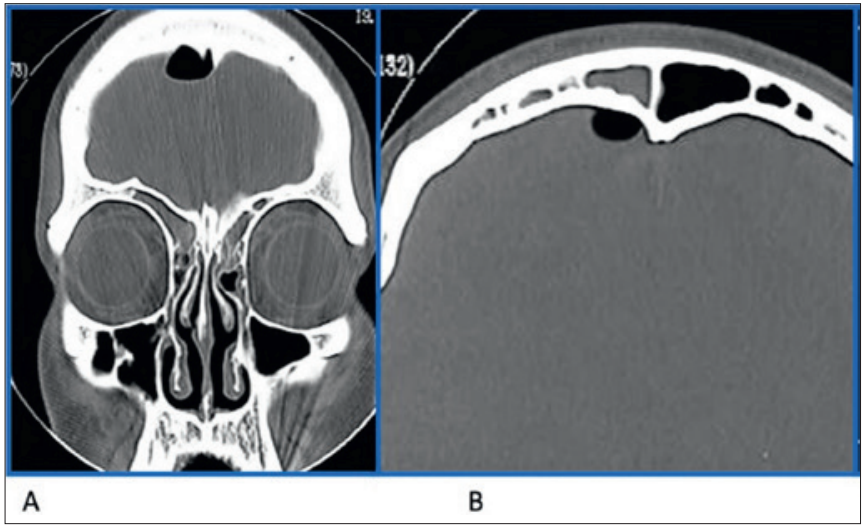

Figure 4. (A-B) CT with pneumocephalus and frontal sinusitis. the nasal septum medially to the lamina papyracea laterally). In Figure 5 we propose a practical algorithm of management of Intracranial complications of ABRS.

\section{Intracranial complications of CRS}

Mucoceles and fungal rhinosinusitis are responsible for intracranial complications of CRS.

\section{Mucoceles}

Sinus Mucoceles are expansile, mucoid-filled, cyst-like lesions that grow over time, they can completely opacify the affected sinus and can deform surrounding structures ${ }^{7}$. 


\section{Intracranial complications of ABRS algorithm}

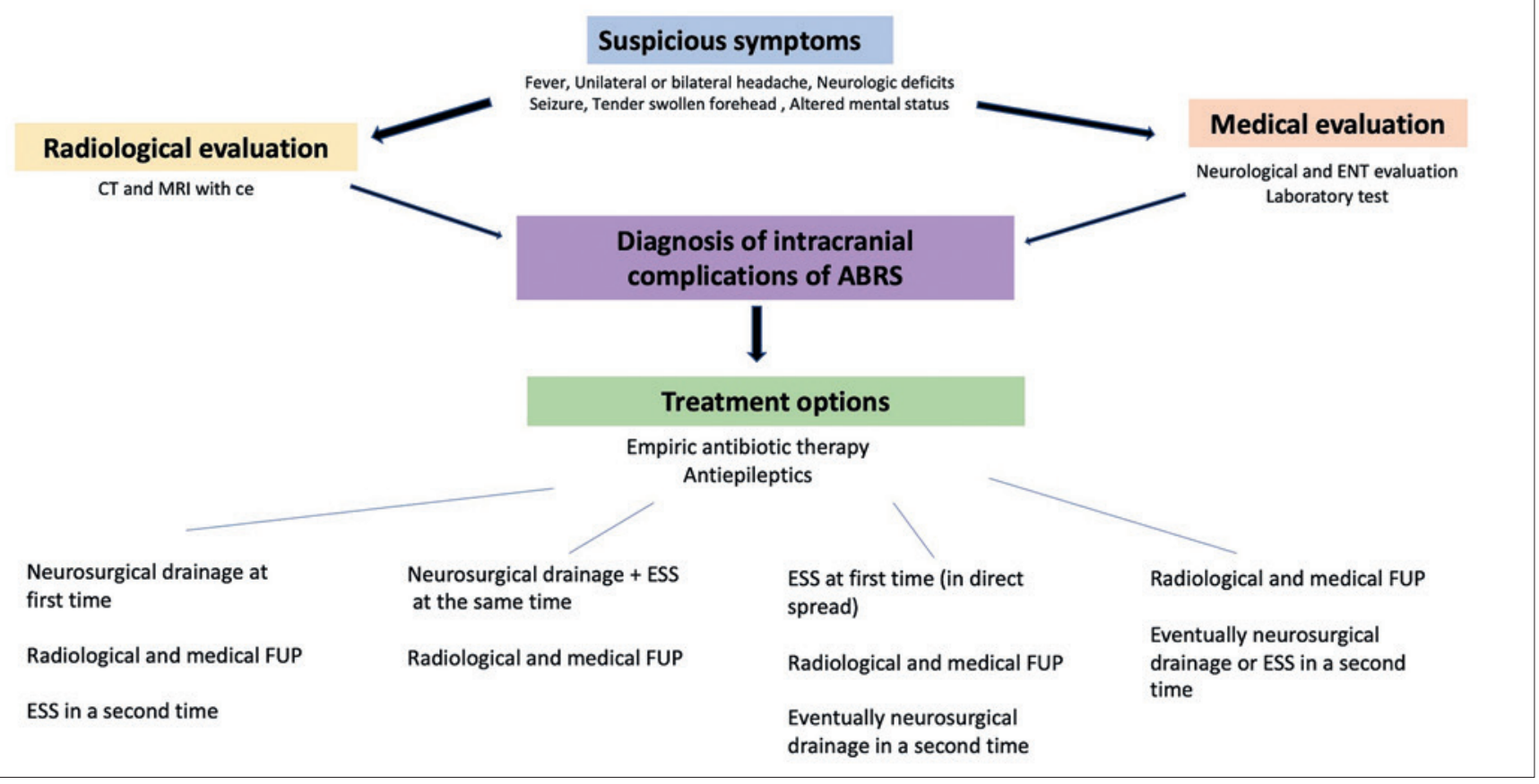

Figure 5. Management of intracranial complications of ABRS algorithm.

They most frequently originate from the frontal and ethmoid sinuses and tend to be unilateral but can be bilateral too ${ }^{8}$.

\section{Etiologic mechanism}

Mucoceles are caused by trapped mucosal elements in the frontal or ethmoid sinuses after obstruction of the normal pathways of aeration ${ }^{21}$. The obliteration of sinus ostium can be congenital or acquired, it can be caused by allergic rhinitis, post-traumatic event, post-inflammation, post-surgery and infective ${ }^{22}$. Whether there is an infectious etiology or if they become secondarily infected, they are termed mucopyoceles. They grow slowly and their pressure induce necrosis and release of natural osteolytic factors that lead to the destruction of surrounding bony structures ${ }^{23}$. Usually they are diagnosed later in their development, only after orbital or cranial invasion has occurred.

\section{Complications and symptoms}

Given the proximity of mucoceles to the brain and to the orbit, significant morbidity and potential mortality may result if these are allowed to grow.

In case of an intracranial extension, they can cause facial pain, headaches, bony erosion of the skull base, leaks of cerebrospinal fluid, brain herniation and infections as men- ingitis ${ }^{24,25}$. Radiological evaluation with $\mathrm{CT}$ and contrast enhancement MRI is mandatory for diagnosis and it is important to plan the surgical treatment.

\section{Treatment}

Mucoceles and its complications are treated surgically. Until the 1980s, the only treatment of mucoceles was surgery using an external route, with large incision and osteoplasty, but this technique didn't restore the normal physiological aeration. In recent years there has been an improvement in the management of mucoceles with the use of nasal endoscopy which nowadays can be considered the first option treatment for this pathology. The endoscopic technique is less invasive than the external approach and is successful as it allows the restoration of sinus drainage. It decreases intra and postoperative morbidity, reducing the operative time, allows a larger view of the lesion and surrounding anatomical structures, reduces chances of recurrence but the success rate is strictly linked to the experience of the surgeon. Another approach found in literature is the combined technique (external approach and endoscopy), which can be used in selected and more complicated cases ${ }^{26}$, depending on the extension of mucoceles and of its intracranial complications. In case of infections (mucopyoceles and meningitis) it is also necessary to administrate antibiotic 
therapy (in Figure 6 we propose a practical algorithm of management of intracranial complications of mucoceles).

\section{Intracranial complications of fungal rhinosinusitis (FRS)}

Between sinonasal fungal infections the ones that can cause intracranial complications are the allergic fungal rhinosinusitis (AFRS) which are included in the non-invasive variant, and the invasive fungal rhinosinusitis (IFRS).

AFRS occurs in immunocompetent atopic patients with hypersensitivity to fungal allergens and rarely can cause intracranial involvement. AFRS and bone erosion may be more prevalent in younger male patients, and in individuals of African American descent ${ }^{27,28}$.

The IFRS can be classified in 3 forms with different clinical and pathologic characteristic depending on the progression of the disease and the immune status of the host ${ }^{29}$. They are categorized into acute invasive form with a course of disease of 4 weeks or less, chronic invasive form and the granulomatous form with a development of more than 12 weeks. These infections occur primarily in immunocompromised patients, with hematologic malignancy, bone marrow transplantation, poorly controlled diabetes, acquired immunodeficiency syndrome, immunosuppressive medications and chemotherapy ${ }^{30}$. Diabetes $(50 \%)$ and hematologic malignancy (40\%) account for $90 \%$ of the immunosuppression reported in over 800 invasive rhinosinusitis patients ${ }^{31}$. It is also proved that the extent and duration of immunodeficiency is proportional to the risk of developing IFRS ${ }^{32}$.

Although less common, there are also case reports describing these infections in people with normal immune function $^{33}$.

\section{Etiologic mechanism}

In the AFRS the allergic mucin and polyps form a partially calcified mass obstructing sinus drainage and tend to involve multiple sinuses ${ }^{34}$. As fungal mucin increases, the involved paranasal sinuses begin to resemble a mucocele and bony remodeling, and decalcification may occur with subsequent nasal, intraorbital, or intracranial involvement mimicking malignancy. Causative agents include dematiaceous (Bipolaris, Curvularia, and Alternaria) and hyaline molds (Aspergillus and Fusarium) ${ }^{35}$.

In the IFRS species most commonly identified are Aspergillus (flavus, fumigatus, terreus, niger) and fungi of the order Mucorales (Zygomycetes) ${ }^{36}$. Fungal infection begins as mucosal inflammation around the middle turbinate and rapidly spreads to the sinuses. Through direct extension or

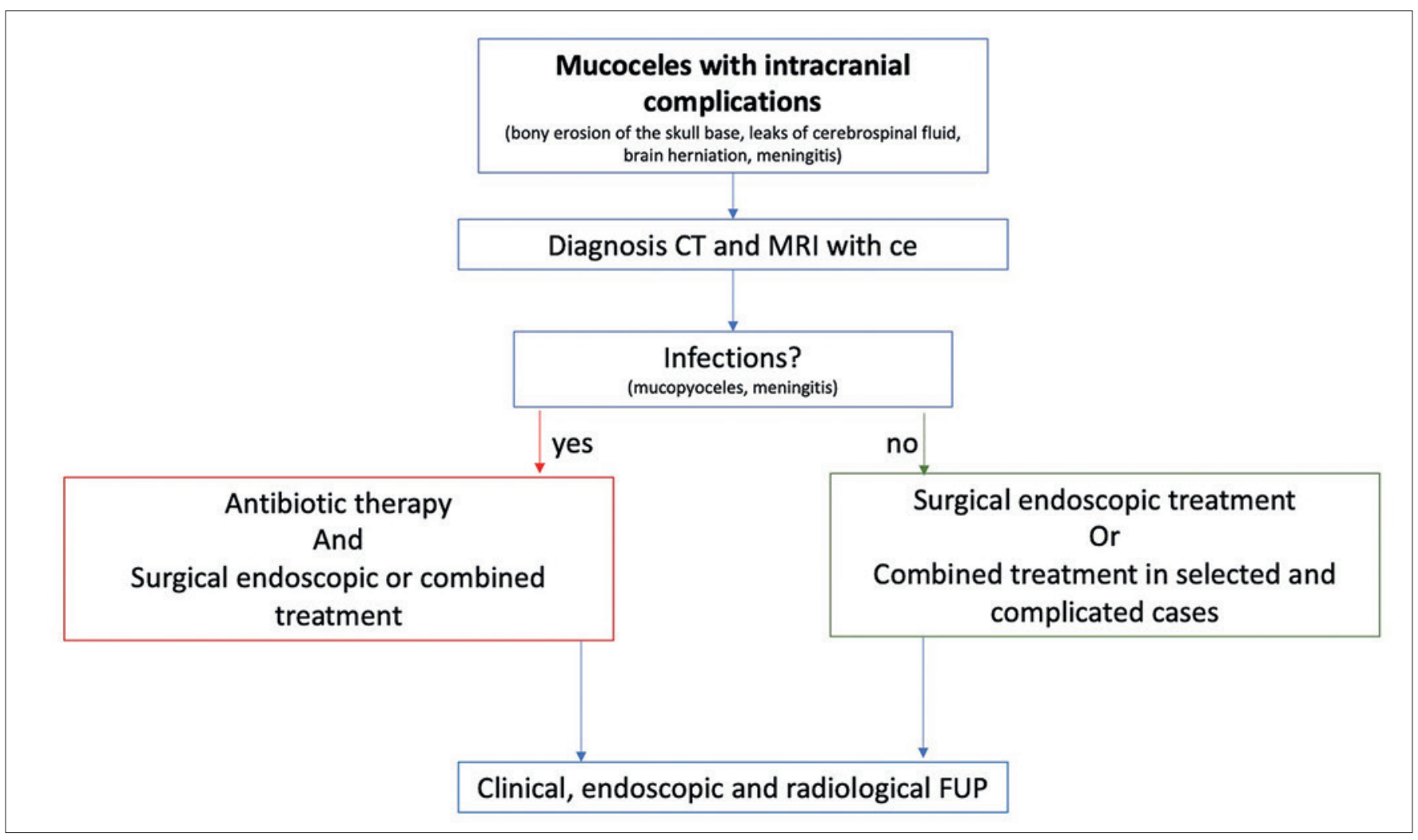

Figure 6. Management of intracranial complications of mucoceles algorithm. ce = contrast enhancement. 


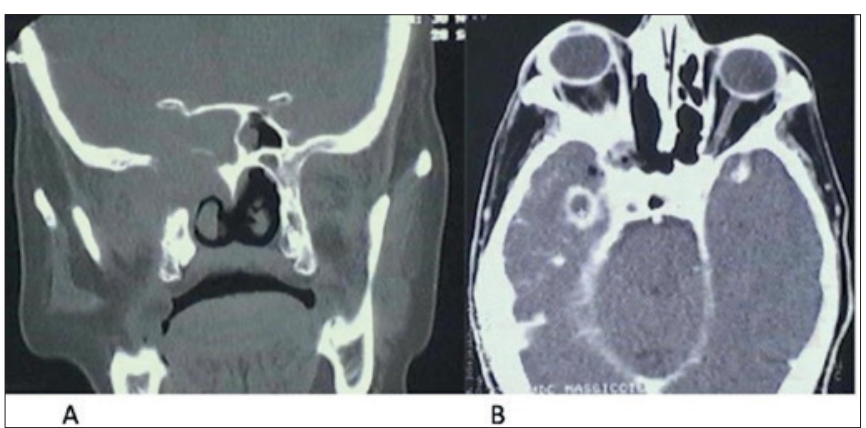

Figure 7. (A) CT with pathological tissue in the nasopharynx with invasion of skull base; (B) CT with contrast enhancement revealed a right brain abscess.

through vascular spread due to their angio-invasive nature it often extends to skull base and brain causing intracranial complications ${ }^{37}$. Hyphal growth into the vessel lumen causes endothelial dysfunction and thrombosis ${ }^{35}$.

\section{Complications and symptoms}

Sinus pain, nasal discharge, low-grade fever, and epistaxis are the most observed symptoms. When orbital symptoms, neurologic deficits and altered mental status occur, they suggest an intracranial involvement (Clinical case of Figure 7: Female 75-year-old with poorly controlled diabetes and blindness of the right eye. She came to hospital with right facial nerve paralysis, impaired right ocular motility and glycemia $900 \mathrm{mg} / \mathrm{dl}$. CT and MRI with contrast enhancement revealed pathological tissue in the nasopharynx with invasion of skull base and also right brain abscess. Nasal endoscopy with biopsy revealed a fungal infection. Treated with endoscopic surgical debridement, amphotericin through endovenous administration and restoring normal glucose level with complete resolution of the infectious process).
Intracranial complications include cavernous sinus thrombosis, parenchymal cerebritis or abscess, meningitis, osteomyelitis, mycotic aneurysm, stroke, and hematogenous dissemination ${ }^{35}$.

\section{Multidisciplinary management}

Diagnosis is made with clinical, radiologic, serologic, and endoscopic data and it should be proven by histologic and microbiological examination.

Nasal endoscopy has shown a good reliability and is very important for an early diagnosis in IFRS ${ }^{38}$. The endoscopic signs of IFRS are commonly located near the middle turbinate, the ethmoid or the septum and include mucosal ischemia, plain necrotic areas with a blackish or grayish color, crusting and absence of bleeding upon scraping. CT is important to show bony changes while contrast enhancement MRI evaluates soft tissue extension and allows a differentiation from neoplastic entities (extremely useful in AFRS). Due to their morbidity and mortality these infections and complications must be urgently recognized to avoid treatment delay.

Diagnosis and treatment require collaborations between otolaryngologists, infectious disease specialists and neurosurgeons; when patients are immunocompromised for hematologic malignancy and bone marrow transplantation it is particularly important that the hematologists promptly recognize risk factor and nasal symptoms (Clinical case of Figure 8: Male, 52-year-old, immunosuppressive therapy for liver transplant. He was hospitalized for mucormycosis with invasion of pterygopalatin fossa, huge frontal abscess and orbital cellulitis. Treated with endovenous antimycotic therapy, endoscopic surgery with aggressive surgical debridement of paranasal sinus and pterygopalatin fossa bilaterally with improvement of symptoms. He died 2 months later for liver failure).

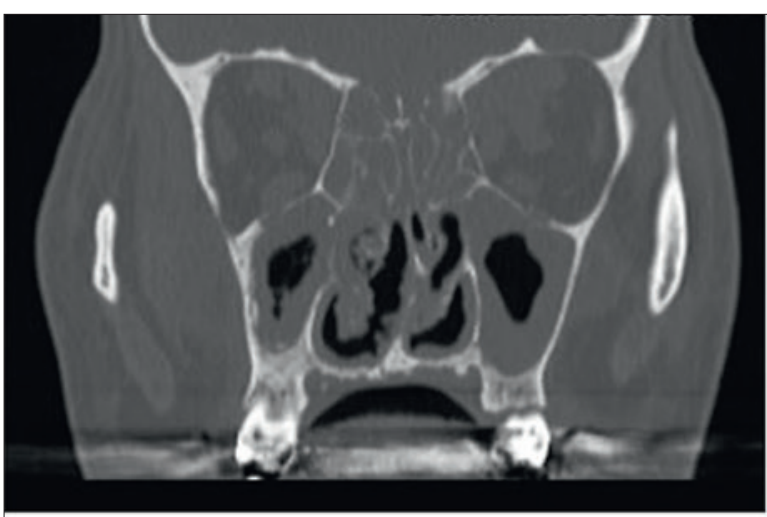

A

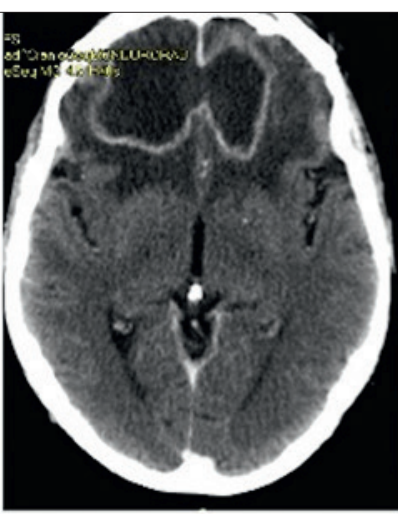

B

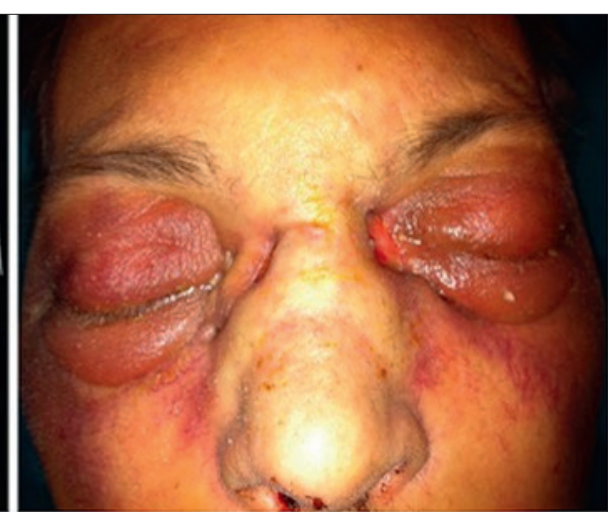

C

Figure 8. (A) CT with mucormycosis of frontal, ethmoidal and maxillary sinuses; (B) CT with huge frontal abscess; (C) orbital cellulitis. 
Table I. Treatment and risk factors of intracranial complication of fungal rhinosinusitis.

$\begin{array}{lcc}\text { Risk factors } & \text { Allergic fungal rhinosinusitis } & \text { Invasive rhinosinusitis (acute chronic, granuloumatous) } \\ \text { Sistory of atopy, allergic rhinitis, asthma } & \begin{array}{c}\text { Hematologic malignancy, bone marrow transplantation, poorly controlled } \\ \text { diabetes, acquired immunodeficiency syndrome, immunosuppressive } \\ \text { medications chemotherapy }\end{array} \\ \text { Medical treatment } & \text { Opening of sinus ostia, polyp and mucin } \\ \text { removal } & \text { Aggressive debridement }\end{array}$

In the AFRS it is important to perform a surgical treatment, to open sinus ostia and remove polyp and mucin, combined with an anti-inflammatory treatment, which include steroids through oral and topic administration, antihistamines and eventually leukotriene antagonists ${ }^{35}$.

Regular follow up is mandatory to check assessment of nasal mucosa and for recurrent endoscopic debridement. Postoperative oral steroid therapy is useful to improve symptoms and prevent early recurrences (Tab. I). Extensive AFRS with intracranial complications are still relatively rare ${ }^{34}$.

The gold standard of IFRS treatment is surgical debridement and systemic empiric antifungal therapy until the causative fungal species is identified $31,36,38$; the most used are amphotericine and voriconazole ${ }^{26}$. The angioinvasion, thrombosis and resulting tissue necrosis make it difficult for chemotherapeutic agents to penetrate the ischemic tissues, that's why surgical debridement of infected and necrotic tissue is considered an essential component of an optimal management ${ }^{39}$ (Tab. I).

These infections represent a life threatening-disease and despite the immediate surgical and antifungal therapy the average mortality remains high when intracranial complications occur. Mortality appears to be related to the extent of disease, with the intracranial extension showing the worse prognosis ${ }^{31}$. Intracranial extension has been shown to be the cause of death in $80 \%$ of cases and the infections is considered almost always fatal in presence of intracranial involvement ${ }^{40}$.

\section{Conclusions}

Whether intracranial complications arise from ABRS or from CRS, they can be life threatening and can significantly impact patient quality of life. Patients with compromised immune system or with multiple risk factors have worse prognosis than immunocompetent patient. Clinicians must be aware of these complications for their potential significant morbidity and mortality, they must promptly recognize symptoms and risk factors to avoid treatment delay. Intracranial complications of ABRS are not predictable as often occur in patients without risk factors or compromised immune system. Each case must be carefully evaluated, the therapeutic approach must be customized, and a multidisciplinary approach is mandatory as there is not a gold standard treatment.

Mucoceles and AFRS rarely cause intracranial complications and often they are approached with a surgical endoscopic treatment followed by antibiotic therapy in case of infection.

Intracranial complications of IFRS have the worse prognosis as they frequently occur in immunocompromised patients with hematologic malignancies or with several comorbidities. A multidisciplinary approach is important for the treatment and mostly for prevention. The recognition of first symptoms in patient with risk factors is fundamental to avoid treatment delay and to improve the outcomes.

\section{References}

1 Younis RT, Lazar RH, Anand VK. Intracranial complications of sinusitis: a 15-year review of 39 cases. Ear Nose Throat J 2002;81:636644. https://doi.org/10.1177/014556130208100911

2 Adame N, Hedlund G, Byington CL. Sinogenic intracranial empyema in children. Pediatrics 2005;116:e461-e467. https://doi.org/10.1542/ peds.2004-2501

3 Patel AP, Masterson L, Deutsch CJ, et al. Management and outcomes in children with sinogenic intracranial abscesses. Int J Pediatr Otorhinolaryngol 2015;79:868-873 https://doi.org/10.1016/j.ijporl.2015.03.020

4 Chaiyasate S, Fooanant S, Navacharoen N, et al. The complications of sinusitis in a tertiary care hospital: types, patient characteristics, and outcomes. Int J Otolaryngol 2015;2015:709302. https://doi. org/10.1155/2015/709302

5 Jones NS, Walker JL, Bassi S, et al. The intracranial complications of rhinosinusitis: can they be prevented? Laryngoscope 2002;112:59-63. https://doi.org/10.1097/00005537-200201000-00011

6 Dayman GL, Adams GL, Paugh DR, et al. Intracranial complications of paranasal sinusitis a combined institutional review. Laryngoscope 1991;101:234-239. https://doi. org/10.1288/00005537-199103000-00003

7 Carr TF. Complications of sinusitis. Am J Rhinol Allergy 2016;30:241245. https://doi.org/10.2500/ajra.2016.30.4322

8 Fokkens WJ, Lund VJ, Hopkins C, et al. European Position Paper on rhinosinusitis and nasal polyps 2020. Rhinology 2020;58(Suppl S29):1-464. https://doi.org/10.4193/Rhin20.600

9 Giannoni CM, Stewart MG, Alford EL. Intracranial complica- 
tions of sinusitis. Laryngoscope 1997;107:863-867. https://doi. org/10.1097/00005537-199707000-00005

10 Gallagher RM, Gross CW, Phillips CD. Suppurative intracranial complications of sinusitis. Laryngoscope 1998;108:1635-1642. https:// doi.org/10.1097/00005537-199811000-00009

11 DelGaudio JM, Evans SH, Sobol SE, et al. Intracranial complications of sinusitis: what is the role of endoscopic sinus surgery in the acute setting. Am J Otolaryngol - Head Neck Med Surg 2010;31:25-28. https://doi.org/10.1016/j.amjoto.2008.09.009

12 Ghobrial GM, Pisculli ML, Evans JJ, et al. Odontogenic sinusitis resulting in abscess formation within the optic chiasm and tract: case report and review. J Neuro-Ophthalmology 2016;36:393-398. https:// doi.org/10.1097/WNO.0000000000000430

13 Adibelli ZH, Songu M, Adibelli H. Paranasal sinus development in children: A magnetic resonance imaging analysis. Am J Rhinol Allergy 2011;25:30-35. https://doi.org/10.2500/ajra.2011.25.3552

14 Stokken J, Gupta A, Krakovitz P, et al. Rhinosinusitis in children: a comparison of patients requiring surgery for acute complications versus chronic disease. Am J Otolaryngol - Head Neck Med Surg 2014;35:641-646. https://doi.org/10.1016/j.amjoto.2014.05.008

15 Osborn MK, Steinberg JP. Subdural empyema and other suppurative complications of paranasal sinusitis. Lancet Infect Dis 2007;7:62-67. https://doi.org/10.1016/S1473-3099(06)70688-0

16 Patel NA, Garber D, Hu S, et al. Systematic review and case report: Intracranial complications of pediatric sinusitis. Int J Pediatric Otorhinolaryn 2016;86:200-212. https://doi.org/10.1016/j. ijporl.2016.05.009

17 Germiller JA, Monin DL, Sparano AM, et al. Intracranial complications of sinusitis in children and adolescents and their outcomes. Arch Otolaryngol - Head Neck Surg 2006;132:969-976. https://doi. org/10.1001/archotol.132.9.969

18 Hicks CW, Weber JG, Reid JR, et al. Identifying and managing intracranial complications of sinusitis in children: a retrospective series. Pediatr Infect Dis J 2011;30:222-226. https://doi.org/10.1097/ INF.0b013e3181f86398

19 Bayonne E, Kania R, Tran P, et al. Intracranial complications of rhinosinusitis. A review, typical imaging data and algorithm of management. Rhinology 2009;47:59-65.

20 Glickstein JS, Chandra RK, Thompson JW. Intracranial complications of pediatric sinusitis. Otolaryngol - Head Neck Surg 2006;134:733736. https://doi.org/10.1016/j.otohns.2005.12.001

${ }^{21}$ Kennedy DW, Senior BA. Endoscopic sinus surgery: a review. Otolaryngol Clin North Am 1997;30:313-330.

22 Yap SK, Aung T, Yap EY. Frontal sinus mucoceles causing proptosis two case reports. Ann Acad Med Singapore 1998;27:744-747.

23 Lund VJ, Henderson B, Song Y. Involvement of cytokines and vascular adhesion receptors in the pathology of fronto-ethmoidal mucocoeles. Acta Otolaryngol 1993;113:540-546. https://doi. org/10.3109/00016489309135860

24 Weitzel EK, Hollier LH, Calzada G, et al. Single stage management of complex fronto-orbital mucoceles. J Craniofac Surg 2002;13:739745. https://doi.org/10.1097/00001665-200211000-00004

25 Severino R, Severino P. Fronto-orbital mucocele with intracranial ex- tension: a case report. J Surg Case Reports 2017;2017:rjx107. https:// doi.org/10.1093/jscr/rjx107

26 Dos Santos, PL, Chihara LL, Azambuja Alcalde LF, et al. Outcomes in surgical treatment of mucocele in frontal sinus. J Craniofac Surg 2017;28:1702-1708. https://doi.org/10.1097/ SCS.0000000000003224

27 Ghegan MD, Wise SK, Gorham E, et al. Socioeconomic factors in allergic fungal rhinosinusitis with bone erosion. Am J Rhinol 2007;21:560-563. https://doi.org/10.2500/ajr.2007.21.3082

28 Wise SK, Ghegan MD, Gorham E, et al. Socioeconomic factors in the diagnosis of allergic fungal rhinosinusitis. Otolaryngol - Head Neck Surg 2008;138:38-42. https://doi.org/10.1016/j.otohns.2007.10.020

29 DeShazo RD, Chapin K, Swain RE. Fungal sinusitis. N Eng J Med 1997;337:254-259. https://doi.org/10.1056/NEJM199707243370407

30 Monroe MM, McLean M, Sautter N, et al. Invasive fungal rhinosinusitis: a 15-year experience with 29 patients. Laryngoscope 2013;123:1583-1587. https://doi.org/10.1002/lary.23978

31 Turner JH, Soudry E, Nayak JV, et al. Survival outcomes in acute invasive fungal sinusitis: a systematic review and quantitative synthesis of published evidence. Laryngoscope 2013;123:1112-1118. https:// doi.org/10.1002/lary.23912

32 Chen CY. Invasive fungal sinusitis in patients with hematological malignancy: 15 years experience in a single university hospital in Taiwan. BMC Infect Dis 2011;11:1-9. https://doi. org/10.1186/1471-2334-11-250

33 Kim DW. Invasive paranasal mucormycosis with peripheral eosinophilia in an immunocompetent patient. Med Mycol 2010;48:406-409. https://doi.org/10.3109/13693780903177790

34 Vashishth A. Extensive allergic fungal rhinosinusitis: ophthalmic and skull base complications. Indian J Otolaryngol Head Neck Surg 2015;67:227-233. https://doi.org/10.1007/s12070-014-0771-x

35 Gavito-Higuera J, Mullins CB, Ramos-Duran L, et al. Sinonasal fungal infections and complications: a pictorial review. J Clin Imaging Sci 2016;6:23. https://doi.org/10.4103/2156-7514.184010

36 Montone KT, Livolsi VA, Feldman MD, et al. Fungal rhinosinusitis: a retrospective microbiologic and pathologic review of 400 patients at a single University Medical Center. Int J Otolaryngol 2012;2012:684835. https://doi.org/10.1155/2012/684835

37 Hoxworth JM, Glastonbury CM. Orbital and intracranial complications of acute sinusitis. Neuroimaging Clin North Am 2010;20:511526. https://doi.org/10.1016/j.nic.2010.07.004

38 Fernandez IJ. Acute invasive fungal rhinosinusitis in immunocompromised patients: role of an early diagnosis. Otolaryngol Head Neck Surg (United States) 2018;159:386-393. https://doi. org/10.1177/0194599818765744

39 Spellberg B, Edwards J, Ibrahim A. Novel perspectives on mucormycosis: pathophysiology, presentation, and management. Clin Microbiol Rev 2005;18:556-569. https://doi.org/10.1128/ CMR.18.3.556-569.2005

40 Safar A, Marsan J, Marglani O, et al. Early identification of rhinocerebral mucormycosis. J Otolaryngol 2005;34:166-171. https://doi. org/10.2310/7070.2005.04023 